\title{
The Brazilian Society of Nephrology and the Covid-19 Pandemic
}

\section{A Sociedade Brasileira de Nefrologia e a pandemia pela Covid-19}

\begin{abstract}
Authors
Andrea Pio de Abreu ${ }^{1,2,3}$ (iD

Miguel Carlos Riella ${ }^{1,2}$ (iD

Marcelo Mazza do Nascimento ${ }^{1,4}$ iD

'Sociedade Brasileira de Nefrologia, São Paulo, SP, Brazil. ${ }^{2}$ Brazilian Journal of Nephrology, São Paulo, SP, Brazil.

${ }^{3}$ Universidade de São Paulo, São Paulo, SP, Brazil.

${ }^{4}$ Universidade Federal do Paraná, Curitiba, PR, Brazil.
\end{abstract}

\section{Correspondence to:}

Andrea Pio de Abreu

E-mail: andreapioabreu@gmail.com

DOI: https://doi.org/10.1590/2175-8239-JBN-2020-S101
Covid-19, a disease caused by the new betacoronavirus, called SARS-CoV-2, was first reported in China In December of $2019^{1}$. On January 30, 2020, the World Health Organization (WHO) declared that the Covid-19 epidemic constituted a Public Health Emergency of International Importance (ESPII) ${ }^{2}$. On February 3, 2020, the Brazilian Ministry of Health (MS) declared a Public Health Emergency of National reach ${ }^{3}$. There had been no cases reported in the country by then, but this happened on February 26, 2020, with confirmation of the first imported case, coming from Italy ${ }^{4}$. On March 11, 2020, the day before World Kidney Day, the WHO declared it to be a pandemic. A few days later, on March 20, the Brazilian Ministry of Health recognized its community transmission throughout the national territory ${ }^{5}$.

There are reports that the infection affects age groups with variable severity spectrum. Most patients who get more severely ill, have pre-existing diseases, or are elderly. Approximately $80 \%$ of the cases are asymptomatic or have mild flu-like symptoms ${ }^{6}$. About $20 \%$ of the cases have worse outcomes, progressing to severe pneumonia, requiring hospitalization. Of these, $5 \%$ are critical, evolving with Acute Respiratory Discomfort Syndrome, having the need for intensive care ${ }^{7}$.

Covid-19 has several and important implications from a nephrological point of view. First, is the kidney involvement, with hematuria and proteinuria; and may progress to acute renal failure (ARF), which occurs mainly in critically ill patients, who may need dialysis. Another implication is that a large number of nephrological patients are part of the risk group for complications from the disease. In addition, there are implications concerning the dialysis treatment of patients undergoing chronic dialysis. Such treatment must continue during the pandemic period, with care and procedures to be adopted by patients, healthcare professionals, dialysis center managers and healthcare authorities.

Faced with this new world scenario, the Brazilian Society of Nephrology (SBN) acted promptly, outlining a plan of recommendations with the support of its various departments and committees, to help nephrologists and healthcare authorities to cope with the various clinical situations resulting from this new disease. Our first recommendation, concerning the care of patients on dialysis, was published on March 1, 2020, preceding the WHO's statement that Covid-19 was a pandemic. Since this is a new virus in Brazil and in the world, the recommendations went hand-in-hand with the evolution of knowledge about the disease, and followed the recommendations and determinations of the Federal Board of Medicine (CFM) and the Ministry of Health (MS). Moreover, the SBN brought together other specialist associations, to make the documents more scientifically robust. In this sense, we published thirteen recommendations and opinions involving the various areas of nephrologists' activities.

The greatest concern during the first cases reported in our country, was about 
Covid-19`s behavior within hemodialysis (HD) units, since social isolation could not be applicable to such population, extremely susceptible to complications of the disease. Thus, the SBN Dialysis Department drew up an "SBN good practices recommendations to dialysis units regarding the epidemic of the new Coronavirus (COVID-19)" listing the main measures to prevent the spread of the virus and, with that, provide greater safety to patients and professionals within these units. Another recommendation that addressed specific aspects of HD was "Maintenance of vascular access during the COVID 19 pandemic", prepared by the SBN Interventional Nephrology Committee. In this document, the committee proposes actions regarding the need to establish new vascular accesses, managing their dysfunction, and intervention procedures that can be considered of emergency or elective during the pandemic.

Still in relation to chronic dialysis, the Peritoneal Dialysis Committee issued the "SBN Good Practices Recommendations to Peritoneal Dialysis Services in Relation to the New Coronavirus (COVID-19) Epidemic", which guides the treatment for this group of patients, both with regards to medical and nursing care during home treatment, as well as care in face-to-face visits. Within these recommendation, telemedicine (tele-guidance, telemonitoring, and tele-consultation) is an important tool, after a letter issued by the CFM (CFM Letter No. 1756/2020) recognizing the possibility of such practice, given the pandemic`s context.

Since the beginning of the pandemic, the running and interpreting tests within the hemodialysis units have been, and continue to be, an important concern of nephrologists. The "SBN Recommendations for approaching Covid-19 diagnostic tests in hemodialysis units", instructs on laboratory tests for Covid-19, the clinical criteria for decision making in the discontinuation of patient isolation, and for healthcare professionals and collaborators with suspicion or confirmation of the disease to return to their practices. We developed practical flowcharts to assist in dialysis routines so that these exams could be interpreted in a practical and objective way within the units.

As far as prevention is concerned, many of the recommendations include important aspects related to the virus contagion aspects, adapting the MS recommendations to the general population, to nephrological patients, as well as to the team of professionals involved in different areas of nephrology. Since the beginning of the pandemic, wearing protection masks has been the subject of intense debate in the scientific and lay communities. Information note No. 3/2020-CGGAP/DESF/ SAPS/MS, in which the MS recommends the use of a cloth mask by the entire population outside the home, was also the object of a statement by our entity through the "SBN Recommendations regarding the use of cloth masks by chronic renal patients on dialysis, during the pandemic of the new coronavirus (COVID-19)". We developed such recommendations with the help of members of the Brazilian Society of Infectious Diseases (SBI), adding greater scientific support to this topic, which has dominated the media and the general public opinion. It is noteworthy that this recommendation establishes the need for healthcare professionals and patients with suspicion or confirmation of the disease to wear surgical masks.

Concerning the clinical management of nephrological patients in the face of this pandemic, we also created recommendations involving several areas of the specialty. There are important guidelines for these patients, described in the "Information for patients with Chronic Kidney Disease (CKD), about the COVID-19 infection", contextualized in clinical nephrology, regarding prevention and treatment, including the use of immunosuppressants. In the "Guidance protocol for colleagues who treat patients with rare kidney diseases due to the SARS COV2 epidemic (Severe Acute Respiratory Syndrome, Coronavirus - 2)", there are general recommendations for patients and nephrologists concerning the management of clinically stable patients and immunosuppressive treatment when necessary, among other guidelines. Where clinical management is concerned, readers will also find recommendations concerning "Palliative care and the Covid-19 pandemic" addressing important concepts related to shared decision-making (staff, patient and family), the priority management of symptoms, and assistance with bereavement.

This supplement also includes how to approach pediatric nephrology patients, through the Department of Pediatric Nephrology, which created the "Recommendations for pediatric patients on hemodialysis, peritoneal dialysis and kidney transplant 
in the Covid-19 (SARS-CoV-2) pandemic", and the "SBN Recommendations for Pediatric Patients on Dialysis during the COVID-19 Pandemic". It also encompasses guidelines concerning the management of children on dialysis, before and after kidney transplantation, as well as those on peritoneal dialysis. It also includes instructions for healthcare professionals, clinics and transplant centers, in addition to a proposed flow chart model for dialysis centers.

In addition to the aforementioned recommendations, SBN issued statements at two different times concerning the prescription of specific drugs. In the first case, the SBN Department of Arterial Hypertension expressed its opinion on "The use of ARS Blockers, especially angiotensin-converting enzyme (ACE) inhibitors and All AT1 receptor antagonists, during the COVID-19 Infection Pandemic". Such a statement was necessary, in view of the broad discussion by the scientific community as to the possible association of these drugs with the greater risk of serious infection by Covid-19. In view of due scientific support, and in line with several national and international opinions, they recommend the continuous use of these classes of drugs, even in individuals suspected or infected by Covid19 , except in cases of hypotension.

In the second case, due to the approval of Opinion No. 04/2020 by the CFM, establishing criteria and conditions for the prescription of chloroquine and hydroxychloroquine in patients with a confirmed diagnosis of Covid-19, we issued the "SBN Note Concerning the Adjustment of Chloroquine and Hydroxychloroquine Drug Doses by Renal Function", to educate on the necessary dose adjustment for patients with chronic kidney disease, stressing the lack of studies, so far, that provide scientific support for the use of these drugs in the treatment of Covid-19.

The Covid-19 pandemic impact on intensive care units in our country is being very intense. Critical patients developing ARF is an increasingly frequent complication, involving diagnostic and therapeutic aspects, which were reasons for the SBN ARF Department to publish this: "Technical Note and Guidelines on Renal Injury Acute (ARI) in COVID-19 patients". It is a robust document prepared together with the Brazilian Association of Intensive Care Medicine (AMIB), on recommendations regarding the diagnosis of ARF, vascular access, as well as the applicable modalities for renal replacement therapy at the bedside, customized to the reality of each location.

We wish to thank all SBN departments and committees for their hard work in formulating these recommendations and statements that now materialized in the form of papers in this special supplement of our Brazilian Journal of Medicine, always maintaining that this work does not end here, being in fact the beginning of a continuous effort to improve these recommendations, which should be periodically updated due to the speed of publications, and the unveiling of Covid-19 pathophysiological mechanisms. This supplement is an example of SBN's effort, which mirrors that of the entire national and international scientific community, in tackling this pandemic, which we have to overcome.

We wish you a good read.

\section{References}

1. Zhu N, Zhang D, Wang W, Li X, Yang B, Song J, et al. A novel coronavirus from patients with pneumonia in China, 2019. N Engl J Med. 2020 Feb;382:727-33. doi:10.1056/NEJMoa2001017

2. Sohrabi C, Alsafi Z, O’Neill N, Khan M, Kerwan A, Al-Jabir A, et al. World Health Organization declares global emergency: a review of the 2019 novel coronavirus (COVID-19). Int J Surg. 2020 Apr;76:71-76. doi: 10.1016/j.ijsu.2020.02.034.

3. Brasil. Ministério da Saúde. Portaria MS/GM no 188, de 3 de fevereiro de 2020. Declara Emergência em Saúde Pública de importância Nacional (ESPIN) em decorrência da Infecção Humana pelo novo Coronavírus (2019-nCoV) [Internet]. Diário Oficial da União, Brasília (DF), 2020 fev; Seção Extra: 1. Disponível em: http://www.in.gov.br/en/web/dou/-/portaria-n-188-de-3-de-fevereiro-de-2020-241408388.

4. Oliveira WK, DuarteE, França GVA, GarciaLP.How Brazilcanhold back COVID-19. Epidemiol Serv Saude. 2020;29(2):e2020044. doi:10.5123/s1679-49742020000200023.

5. Ministério da Saúde (BR). Ministério da Saúde declara transmissão comunitária nacional [Internet]. Brasília: Ministério da Saúde; 2020. Disponível em: https://www.saude.gov.br/ noticias/\%20agencia-saude/46568-ministerio-da-saude-declaratransmissao-comunitaria-nacional

6. Guan WJ, Ni ZY, Hu Y, Liang WH, Ou CQ, He JX, et al. Clinical characteristics of coronavirus disease 2019 in China. N Engl J Med. 2020. Disponível em: https://doi.org/10.1056/ NEJMoa2002032.

7. Zhou F, Yu T, Du R, Fan G, Liu Y, Liu Z, et al. Clinical course and risk factors for mortality of adult in patients with COVID19 in Wuhan, China: a retrospective cohort study. Lancet. 2020 Mar 28;395(10229):1054-1062. doi: 10.1016/S01406736(20)30566-3. 